\title{
Médiévales
}

Langues, Textes, Histoire

66 | printemps 2014

Harmonie Disharmonie

\section{Z. David ZUWIYYA (éd.), A Companion to Alexander \\ Literature in the Middle Ages}

Leyde, Brill (« Brill's Companions to the Christian Tradition », 29), 2011, $409 \mathrm{p}$.

Sébastien Garnier

\section{(2) OpenEdition}

Journals

Édition électronique

URL : https://journals.openedition.org/medievales/7294

DOI : 10.4000/medievales.7294

ISSN : $1777-5892$

Éditeur

Presses universitaires de Vincennes

Édition imprimée

Date de publication : 30 juin 2014

Pagination : 204-206

ISBN : 978-2-84292-405-8

ISSN : 0751-2708

Référence électronique

Sébastien Garnier, "Z. David zuwiry (éd.), A Companion to Alexander Literature in the Middle Ages », Médiévales [En ligne], 66 | printemps 2014, mis en ligne le 10 juillet 2014, consulté le 22 avril 2022.

URL : http://journals.openedition.org/medievales/7294; DOI : https://doi.org/10.4000/medievales. 7294

Ce document a été généré automatiquement le 22 avril 2022.

Tous droits réservés 


\section{Z. David zuWIYYA (éd.), A Companion to Alexander Literature in the Middle} Ages

Leyde, Brill (« Brill’s Companions to the Christian Tradition », 29), 2011, $409 \mathrm{p}$.

Sébastien Garnier

\section{RÉFÉRENCE}

Z. David ZUWIYYA (éd.), A Companion to Alexander Literature in the Middle Ages, Leyde, Brill («Brill's Companions to the Christian Tradition », 29), 2011, 409 p.

1 Spécialiste du Roman alexandrin, Z. D. Zuwiyya coordonne ici un ouvrage qui se propose d'inventorier richement la postériorité des récits traitant de l'épopée d'Alexandre le Grand dans la littérature médiévale - cinquante-cinq ans après G. Cary en faisant ressortir la généalogie, ascendante comme descendante, de ces traditions. Eu égard à la nature composite de ce vaste vadémécum, nous maintiendrons dans les lignes qui suivent sa structure encyclopédique.

R. Stoneman examine les sources primaires: le Pseudo-Callisthène, l'Histoire latine de Quinte-Curce (globalement encomiaste), mais aussi un Itinerarium, des épitomés ou encore des épîtres (celle adressée à Aristote narre l'expédition «fabuleuse » en Inde). Pierre de fondation de toute la tradition européenne médiévale, l'Historia de preliis connut une diffusion remarquable à travers un grand nombre de langues vernaculaires au bas Moyen Âge, au point que son héros « devint un exemple pour les moralistes et les théologiens, un véhicule scientifique pour l'époque, un modèle pour les rois et les empereurs, ainsi qu'un emblème de la vie humaine s'élevant parfois même au niveau de celle de Jésus» (p.19). S. Dönitz étudie l'entrée de ce roi "gentil» dans les écrits judaïques qui agrégèrent des traductions (à partir de textes grecs et/puis arabes) à une littérature «didactique». Au gré des contextes politiques, «la littérature rabbinique 
fait montre d'une attitude ambivalente à l'égard d'Alexandre»(p. 23), dont les différents épisodes évoquent le motif des limites de l'expérience humaine sans cesse repoussées sous l'effet de l'hybris. Pour J. P. Monferrer-Sala, la version syriaque issue du Pseudo-Callisthène «représente la version orientale ayant eu la plus grande influence » (p. 41). Le milieu nestorien nord-mésopotamien enfanta ce Roman (ca 628) aux couleurs apocalyptiques. Inséré à la fin du texte - aux côtés de la légende de la source de vie (" comme si elles appartenaient à un autre cycle ", p. 55) - le topos de Gog et Magog trahit une obsession eschatologique. Ces deux ajouts retracent les actes d'un roi que guide un dieu monothéiste : la mission divine dicte la narration édificatrice. L'empereur Héraclius triomphant put se glisser sous les traits du cosmocrator christianisé et confirmer la fonction sotériologique à l'œuvre. De plus, l'inclusion [apocryphe] de la lettre d'Aristote singularise ledit texte, tout comme l'expédition menée au-delà de l'oxus en Asie centrale et en Chine. L'ensemble égrène une succession de «sagas » et se laisse diviser en trois sections inégales et génériquement complexes: 1) jeunesse, 2) campagnes militaires, 3) mort. La dernière, testamentaire, propose une imitation à diffuser.

3 Les histoires attachées au conquérant macédonien circulèrent (à partir du syriaque) en Arabie ( $\left.\mathrm{vi}^{\mathrm{e}} \mathrm{s} . \mathrm{ap} . \mathrm{J} .-\mathrm{C}.\right)$ puis intégrèrent le Coran $(18,83-98)$. Les historiographes et exégètes étoffèrent sa geste en puisant dans le riche matériel du Roman. Du corpus retenu par Z. D. Zuwiyya - deux textes transmis par 'Abd al-Raḥmān b. Ziyād (m. 718), un Ḥadīt (xve s.), la Qișșa de 'Umāra b. Zayd (fl.viII ${ }^{\mathrm{e}}$ s.) et le Ta'rīH al-Iskandar d'al-Ṣūīi (fin XIII ${ }^{\mathrm{e}} \mathrm{s}$.) - deux facettes contradictoires saillent : «celle d'un conquérant extrêmement zélé et, à ce titre, blâmable - comme le dépeint souvent le Pseudo-Callisthenes et sa tradition -, mais aussi le pieux "ami de Dieu" représenté dans le Coran» (p. 98). La trame générale articule des campagnes militaires (suscitées par la prédication) et des épreuves initiatiques. J. Wiesehöfer esquisse l'image d'un «aventurier maudit (gizistag)»: «deux différentes traditions d'Alexandre [co]existent en Iran» (p. 114). Primo, une "histoire nationale iranienne » brosse un tableau «zoroastrianisé » et négatif de l'homme du Rum semant le chaos en Iran. Secundo, l'Alexandre du PseudoCallisthène finit par s'imposer - notamment par la diffusion auprès de la noblesse sassanide d'une recension syriaque (un phénomène accentué dans le Shahnameh islamisé d'al-Firdawsī). D. L. Selden analyse les spécificités de l'Alexandre de la littérature égyptienne: la prise d'Élam, les dernières volontés de Selpharios et la retraite du Chaos de Gédrosie. Ce dernier récit entrelace trois visions culturelles de la royauté : celle de l'Alexandre-pharaon, gardien de l'ordre et de la justice; celle de l'Alexandre-basileus, primus inter pares doué de force et de métis; celle, enfin, de l'Alexandre-messie, témoin éprouvant la résurrection des corps. Le Zēnā Eskender ( $\mathrm{P}$. C. Kotar), une création autochtone en langue guèze ( $\operatorname{xIV}^{\mathrm{e}} \mathrm{s}$.), descend d'un Roman en arabe. Reprise augmentée des Histoires arabes d'al-Makīn et d'Abū Šākir (XIII ${ }^{\mathrm{e}}$ s.), elle aboutit à deux types différents : a) un stratum historique mêlé de nombreuses fictions (cf. Pseudo-Callisthène) ; b) une histoire fabuleuse, i.e. de pure imagination ( $c f$. le Roman chrétien). Un long processus de déshistoricisation transforma le noyau autonome en une matrice capable d'absorber «de nouveaux récits, légendes et mythes» (p.167), pour culminer "dans le "Roman chrétien", œuvre d'un Éthiopien rédigée dans un monastère afin d'édifier les moines" (p.175). L'évêque Gautier de Châtillon au $\mathrm{XII}^{\mathrm{e}}$ siècle dédia l'Alexandréide au comte Guillaume de Champagne (M. Lafferty). Ses dix livres en hexamètre montrent (à partir du Quinte-Curce) un Alexandre désireux de devenir le Roi des Rois au point de franchir l'Océan. Le style fortement hyperbolique 
supporte une lecture édificatrice. Somme d'exempla (modèle du roi croisé) ou attaque portée à l'hybris du roi païen?

Plus généralement, L. Harf-Lancner lie au développement de la classe des chevaliers (au $\mathrm{XII}^{\mathrm{e}} \mathrm{s}$.) la mise en roman (i.e.translatio) de la geste d'Alexandre qu'inspira l'épitomé de Jules Valère. Si plusieurs couches composent le récit français, il revient à Alexandre de Bernay de lui avoir conféré une unité (après 1180). La problématique générique chanson de geste ou roman? - met en relief le rôle crucial rempli par la quête individuelle dont le parangon incarne conquête universelle, savoir et générosité (p. 215). Ce Miroir - « une mise en garde contre la dangereuse délégation du pouvoir aux serviteurs roturiers qualifiés, pour la circonstance, de "serfs" " (p. 217) - prône l'union du sage (Aristote) et du roi (Alexandre), entendez celle des clercs et des chevaliers. L'Inde y fonctionne comme un espace liminaire - lieu de rêve (richesses) et de cauchemar (bestiaire fabuleux, monstres, désert) -, promettant l'immortalité ou le paradis terrestre.

5 Pour l'Espagne, le Libro de Alexandre (première moitié du XIII ${ }^{e}$ siècle) tire son canevas de l'Alexandréide. Assoiffé de savoir, Alexandre exprime la quintessence du héros épique espagnol. Couronnement, conquête et exploration participent d'un didactisme médiéval porté par le contemptus mundi, «lorsque le héros concentre tous ses efforts vers la vie ici-bas au détriment de celle dans l'au-delà » (p. 241). Z. D. Zuwiyya indique d'autres textes médiévaux se rapportant à Alexandre, surtout des recueils de vulgarisation philosophique établis à partir de l'arabe. La tradition d'Alexandre épouse la littérature anglo-saxone (D. Ashurt) dès les rédactions en vieil anglais où la figure de ce dernier est globalement avantageuse quoiqu'adossée à l'Histoire d'Orose (hostile aux rois païens). Après la conquête normande, elle réapparaît au XIV siècle : en vers (Kyng Alisaunder, textes fragmentaires) comme en prose. Elle traverse The Dicts and Sayings of the Philosophers (issu du Bocados de Oro), mais aussi des versions vernaculaires du Secretum Secretorum, des exempla et des chroniques. Le domaine (moyen) écossais accueille deux romans versifiés qui érigent King Alexander en modèle idolâtré de chevalerie: il demeurera une référence littéraire et poétique au-delà de sa propre tradition.

6 Dans le champ germanophone (D. Buschinger), l'Alexanderlied, adapté du poème français d'Albéric de Pisançon par Lamprecht, nous est parvenu à travers la version de Vorau. L'Alexandre de Strasbourg procède de cette dernière. Le Macédonien y donne la mort à son ennemi Darius. Le voyage en Orient livre une quête curieuse de l'autopsie des merveilles. Le personnage n'est pas en proie à la «folle errance» de son équivalent français et parcourt un monde plus réel. De transgresseur il se mue en res iustus et pacificus, devenant une leçon. Étayent cet examen un Miroir de Rudolf von Ems (xIII ${ }^{\mathrm{e}} \mathrm{s}$ ), le long poème courtois eulogico-légitimateur de Ulrich von Etzenbach, celui de Wernigerode (fin XIV ${ }^{e}$ s.) mettant en garde contre la superbe, celui, enfin, de Hartlieb un exemplum édifiant en prose -, postérieur à 1450 et ayant connu une diffusion imprimée.

7 Le monde scandinave (D. Ashurt et $\mathrm{F}$. Vitti) reçut la légende du Macédonien à travers trois principaux ensembles. Le premier, celui de la Saga, voit le prêtre islandais Brandr Jónsson (m. 1264) paraphraser en vieux norrois l'œuvre de Gautier de Châtillon pour soumettre un Miroir au roi norvégien Magnus. Le deuxième, pendant organique du précédent, traduit vers 1250-1350 de manière abrégée l'Epistola Alexandri ad Aristotelem pour donner le Bréf Alexandri Magni. Le troisième, vers 1375-1386, offre avec le Konung 
Alexander une version métrique de type knittel en vieux suédois de l'Historia de preliis, en étoffant avec force détails un canevas narratif initialement sec.

Dans l'Italie du Milione, les aventures célestes et sous-marines ne manquèrent pas de fasciner : «Des histoires concernant Alexandre devinrent l'histoire par excellence pour maints écrivains ainsi que pour tous ceux qui manifestaient de la curiosité envers le monde situé par-delà la Méditerranée.» (p.336) Ni courtois (à la française), ni démoniaque (à l'allemande), le héros oscille entre le fabuleux et le réel. R. Morosini mentionne maints auteurs, dont Boccace, ainsi qu'un Alexandre aux Enfers et des ouvrages tardifs dépeignant un Alexandre urbain, chevalier adoubé seigneur.

9 Somme comparatiste précieuse, cet ouvrage aurait gagné à comporter une synthèse organisant la richesse des matériaux proposés (points archétypaux, variantes et particularités régionales) et complétée par une carte reliant chronologiquement les espaces de réception évoqués. Il aurait ainsi avantageusement relié les quatorze chapitres en mettant en évidence les filiations unissant ces traditions, le rôle crucial joué par certaines, ainsi que la grande diversité générique qui les supportent. De là, gageons qu'un travail ultérieur saura rendre compte de l'élaboration réussie des figures alexandrines complexes au gré des contraintes idéologiques posées par les cultures productrices/consommatrices et de phénomènes clés s'y rattachant: monothéisation, hybris, européanisation, pour ne citer que ceux-là. 